OPEN ACCESS

Edited by:

Arjun Sahgal,

University of Toronto, Canada

Reviewed by:

Riccardo Soffietti,

University of Turin, Italy

Alfredo Conti,

Università degli Studi di Messina, Italy

Parneet K. Cheema

William Osler Health System, Canada

*Correspondence:

Priscilla K. Brastianos

pbrastianos@mgh.harvard.edu

Specialty section:

This article was submitted to

Neuro-Oncology and Neurosurgical

Oncology,

a section of the journa

Frontiers in Oncology

Received: 04 November 2018

Accepted: 04 February 2019

Published: 04 March 2019

Citation:

Venur VA, Cohen JV and Brastianos PK (2019) Targeting Molecular Pathways in Intracranial Metastatic Disease.

Front. Oncol. 9:99.

doi: 10.3389/fonc.2019.00099

\section{Targeting Molecular Pathways in Intracranial Metastatic Disease}

\author{
Vyshak Alva Venur, Justine V. Cohen and Priscilla K. Brastianos* \\ Divisions of Neuro-Oncology and Hematology/Oncology, Departments of Neurology and Medicine, Massachusetts General \\ Hospital, Harvard Medical School, Boston, MA, United States
}

The discovery and clinical application of agents targeting pivotal molecular pathways in malignancies such as lung, breast, renal cell carcinoma, and melanoma have led to impressive improvements in clinical outcomes. Mutations in epidermal growth factor receptor (EGFR), and rearrangements of anaplastic lymphoma kinase (ALK) are targetable in lung cancer, while BRAF mutations have been successfully targeted in metastatic melanoma. Targeting estrogen receptors, cyclin dependent kinases, and HER2 (Human Epidermal Receptor) have resulted in improvement in survival in breast cancer. Major strides have been made in the management of metastatic renal cell carcinoma by targeting the vascular endothelial growth factor (VEGF) pathway. However, intracranial metastases remain a major hurdle in the setting of targeted therapies. Traditional treatment options for brain metastases include surgery, whole brain radiation therapy (WBRT), and stereotactic radiosurgery (SRS). Surgery is effective in symptomatic patients with dominant lesions or solitary intracranial metastases, however, recovery time can be prolonged, often requiring an interruption in systemic treatment. WBRT and SRS provide symptomatic relief and local control but data on improving overall survival is limited. Most targeted therapies which provide extracranial control have limited penetration through the blood brain barrier. Given the limited therapeutic options and increasing prevalence of brain metastases, finding new strategies for the management of intracranial metastatic disease is critical. Genomic analysis of brain metastases has led to a better understanding of variations in the driver mutations compared to the primary malignancy. Furthermore, newer generations of targeted agents have shown promising intracranial activity. In this review, we will discuss the major molecular alterations in brain metastases from melanoma, lung, breast, and renal cell carcinoma. We will provide an in-depth review of the completed and ongoing clinical trials of drugs targeting the molecular pathways enriched in brain metastases.

Keywords: brain metastases (BM), targeted therapy, breast cancer, lung cancer, melanoma

\section{INTRODUCTION}

Brain metastases, a common manifestation of advanced solid malignancies, are associated with significant morbidity and mortality. The incidence of brain metastases varies with primary tumor type, and the overall estimate of the incidence is unclear. Lung cancer is the most common cause of brain metastases; small cell lung cancer contributes to up to $50 \%$ of brain metastases from lung cancer (1). Breast cancer is the second most common cause of brain metastases; about half of 
all brain metastases in breast cancer patients occur in HER2 (human epidermal growth factor-2) overexpressing breast cancer, followed by triple negative breast cancer, and hormone receptor positive breast cancer (2). The highest frequency of brain metastases is seen in patients with metastatic melanoma. Approximately $50 \%$ of metastatic melanoma patients are diagnosed with brain metastases, while an additional $40 \%$ are noted to have brain metastases at autopsy (3).

Due to a paucity of reliable animal models with brain metastases, our understanding of the underlying mechanisms of brain metastases is limited. Metastasis is a complex multistep process that includes cell proliferation, invasion of basement membrane, intravasation into blood circulation, survival in blood stream, organ tropism, extravasation, and colonization into specific organs (4). At each step the cell interacts with its surroundings and is under constant survival pressure. A critical component in this process is the epithelial to mesenchymal transformation (EMT) (5). Similarly, when the metastatic cell exits the blood stream and enters the destination organ it again changes from mesenchymal to epithelial phenotype (MET). Multiple genetic and epigenetic factors play a role in EMT and MET, SMAD and non-SMAD signaling, MAP kinase pathway including BRAF alterations, and PI3K/AKT pathway (6-11).

\section{BLOOD BRAIN BARRIER}

The presence of the blood brain barrier (BBB) makes brain metastases unique compared to other sites of metastases. The $\mathrm{BBB}$ serves a protective role by restricting the movement of cellular components and solutes between systemic circulation and brain. It is comprised of endothelial cells with tight junctions on the systemic circulation side, and pericytes, astrocyte endfoot, and nerve endings on the neuronal side (12). Several efflux transporters of the ATP-binding cassette (ABC) gene family, such as the P-glycoprotein (P-gp) and breast cancer resistance protein (BCRP), are upregulated in the endothelial cells of the $\mathrm{BBB}$. These transporters, in addition to being drug specific transporters, play a crucial role in the elimination of toxins and drugs from the CNS (13). While the endothelial barrier restricts the movement of cells across the $\mathrm{BBB}$, it may paradoxically enable the transmigration of malignant cells during the process of diapedesis. The exact mechanism of $\mathrm{BBB}$ penetration is unknown however there is data to suggest extravasation of malignant cells which proliferate intravascularly, damage the vessels, and disrupt the $\mathrm{BBB}$, thereby leading to metastases formation. Once the metastatic cells are intracranial, the protective BBB limits the immune surveillance and penetrance of systemic therapies (12). Data from Osswald et al. shows brain metastases can be effectively targeted by certain drugs that are designed to cross the BBB, specifically, small molecular inhibitors (14). Similarly, the blood-tumor barrier (BTB) significantly impacts the efficacy of therapeutic agents in brain metastases. This was clearly described by Lockman et al. (15) with an analysis of the variable permeability of brain metastases from breast cancer human and murine models, impeding the delivery of therapeutic drugs into metastases. Additionally, MRI contrast enhancement to electron-dense tracers demonstrates increased BTB permeability in some brain metastases $(16,17)$. Since measurements of drug levels in active brain metastases are difficult to obtain, data on the exact mechanism of the BTB is limited. Published results emphasize the need for molecularly targeted therapies with a higher potential for penetration of the BTB in order to reach therapeutic levels within tumors (18).

\section{GENOMICS OF BRAIN METASTASES}

The advent of more efficient next-generation sequencing techniques have enhanced our understanding of genomic alterations in brain metastases. Whole exome analysis of brain metastases and matched primary tumor from 86 patients showed genomic heterogeneity and branched evolution (19). These results indicate that although metastatic sites share common genes with primary tumors, they develop unique genetic alterations, providing survival advantage in the brain (19). This study also revealed increased frequency of PI3K/Akt, $m T O R, C D K$ alterations in brain metastases. Another relevant study analyzed 16 melanoma brain metastases and matched extracranial sites, with hotspot mutations, mRNA expression patterns, protein expression and activation, and copy number variations (20). The PI3K/Akt pathway was enriched in the brain metastases. Overall similarity was noted in most other driver mutations. A multicenter next generation sequencing and gene expression study of $\sim 17,000$ unmatched primary tumors from non-small cell lung cancer (NSCLC), breast cancer and melanoma demonstrated higher TOP2A expression in brain metastases (21). There was also increased expression of proteins critical in DNA synthesis and repair. This research provides important genetic information for future drug development in the treatment of brain metastases.

\section{ALK FUSIONS AND OTHER GENE FUSIONS}

Anaplastic lymphoma kinase $(A L K)$ fusions were first noted in a subset of anaplastic large cell lymphoma (22) with translocations involving $A L K$ on chromosome $2 \mathrm{p}$ and molecular partners such as NPM-ALK, TPM3-ALK, and TFG-ALK (23). ALK fusions occur in $\sim 3 \%$ of non-small cell lung cancer (NSCLC). The identification of inversions of echinoderm microtubuleassociated protein-like 4 (EML4) with $A L K$ in Japanese women with lung cancer led to the development of drugs targeting $E M L 4-A L K$ fusions (24). This aberrant fusion leads to activation of ALK kinase and downstream signaling pathways including the RAS-mitogen-activated protein kinase (MAPK), JAK-STAT and, phosphoinositide 3-kinase (PI3K) -AKT. One study estimates the incidence of brain metastases in ALK-fusion harboring NSCLC (ALK-NSCLC) to be $>45 \%$ in 3 years (25). Several tyrosine kinase inhibitors (TKI) are developed for the management of ALK-NSCLC. Crizotinib, the first FDA approved TKI for ALK-NSCLC, has limited CNS penetration with a CSF serum ratio of $<0.1$ to $0.26 \%(26,27)$. The phase 3 clinical trial of crizotinib in ALK-NSCLC included 79 patients with previously 
treated and stable brain metastases, with 39 randomized to receive crizotinib while 40 received chemotherapy (28). The intracranial disease control rate at 12 weeks was $85 \%$ in patients treated with crizotinib compared to $45 \%$ in those treated with chemotherapy ( $p<0.001)(29)$. A retrospective analysis of two randomized clinical trials of crizotinib in treatment naïve ALKNSCLC showed that $20 \%$ of the patients who had extracranial disease progression, developed new brain metastases (30). In summary, although crizotinib provides better intracranial disease control, it has poor CNS penetration and 1 in 5 patients treated with crizotinib develop brain metastases.

The next generation of ALK inhibitors, including ceritinib and alectinib, have improved intracranial activity. The ASCEND1 , a phase 1 trial of ceritinib, included 124 patients with stable brain metastases (31). Data for measurable intracranial lesions was available for 14 patients, 10 of whom had prior exposure to an ALK inhibitor. Intracranial responses were reported in 7 patients and 3 had stable disease. In a phase 2 trial of ceritinib, 100 of 140 total patients had brain metastases, however, only 20 had measurable target lesions. The intracranial response rate was $45 \%$, demonstrating good CNS activity (32).

Alectinib is another ALK inhibitor that has been studied in patients with brain metastases. A phase 3 Japanese study compared alectinib to crizotinib in ALK-NSCLC (J-ALEX study). In the analysis of 207 patients, 43 had brain metastases at enrollment. The 1-year cumulative incidence rates for intracranial progression was lower in alectinib group at $5.9 \%$ compared to $16.8 \%$ in the crizotinib group (33). Similar results were reported in the international phase 3 trial comparing alectinib to crizotinib (ALEX) in newly diagnosed metastatic ALK-NSCLC where 18 of the 152 patients (12\%) in the alectinib group and 68 of the 151 patients (45\%) had CNS progression at 18 months (34). All patients in the study had MRI brain at enrollment. The time to CNS progression was longer in patients' treatment with alectinib compared to crizotinib, additionally, 12month cumulative incidence of brain metastases was $41.4 \%$ in the crizotinib group compared to $9.4 \%$ in the alectinib group. Data from two phase 2 studies of alectinib were pooled to evaluate the intracranial efficacy and included 136 patients with brain metastases from ALK-NSCLC who had progressed on crizotinib (35). The CNS disease response rate was $64 \%$. In conclusion, alectinib has better CNS activity compared to crizotinib.

There is early clinical data to support intracranial activity with a new ALK inhibitor, brigatinib. Up to $70 \%$ of patients with crizotinib resistant ALK-NSCLC in the early phase clinical trials of brigatinib had brain metastases (36). In total, 59 patients had measurable brain metastases, and 31 (53\%) of them had intracranial responses to brigatinib. Another exploratory analysis of two phase 2 clinical trials confirmed the intracranial activity of brigatinib (37). Phase 3 clinical trial with brigatinib are showing promising results (38).

ROS1 fusions are reported in $2 \%$ of advanced NSCLC (39). Approximately $20 \%$ of these patients have brain metastases at diagnosis (40). Crizotinib also has activity against ROS1 fusion, however, as mentioned earlier, it has limited intracranial penetration (41). Lorlatinib is a TKI with activity in ROS1 fusion NSCLC, and preliminary results from an ongoing phase 2 study indicate intracranial responses in 3 of 12 patients with brain metastases (42).

The TRK family of tyrosine kinases, TRKA, TRKB, and TRKC are encoded by NTK genes (43). NTK gene fusions lead to activation of the TRK receptors, which increase cell proliferation and survival by PI3K and Ras/MAPK/ERK pathways. Entrectinib is a TKI with activity against $A L K, R O S 1$, and NTRK gene fusions. In a phase 1-2 clinical trial of entrectinib, 5 of the 8 patients with primary or metastatic disease to the brain demonstrated intracranial responses (44). Larotrectinib is another NTK fusion inhibitor in clinical development. Although this drug showed limited CNS penetration in preclinical studies, one patient with NSCLC in the phase I study had $18 \%$ reduction in the size of brain metastases (45).

LOXO-292 selectively targets RET and early studies show activity against activating RET fusions/mutations. Drilon et al. recently presented data from a phase I study of patients with RET fusion \pm malignancies including NSCLC, papillary thyroid cancer, and medullary thyroid cancer $(42,46)$. The NSCLC cohort included 3 patients with brain metastases with a significant reduction in the tumor burden suggesting activity in the brain. BLU-667 is another highly selective RET inhibitor which shows promise in patients with brain metastases (47).

\section{BRAF MUTATION}

V-raf murine sarcoma viral oncogenes homolog B1 (BRAF) is a potent activator of the mitogen-activated protein kinase (MAPK) signaling pathway. The RAS/BRAF/MAPK/ERK pathway, critical for cell survival and proliferation, is altered in $\sim 30 \%$ of all malignancies (48). The BRAF gene mutation has been identified in melanoma, lung, colon, and thyroid cancers (49). In melanoma, $B R A F^{V 600 E}$ mutation accounts for $90 \%$ of all $B R A F$ mutations, while $B R A F^{V 600 K / R / D}$ are less common (50).

Up to $50 \%$ of all advanced melanoma patients harbor $B R A F$ mutations, making it a good target for BRAF inhibitors. Conservative estimates suggest that about $20 \%$ of $B R A F$ mutant metastatic melanoma patients develop brain metastases (51).

Early studies with BRAF inhibitors show intracranial activity. An intracranial response rate of $16 \%$ was noted with single agent vemurafenib in unresectable brain metastases from metastatic melanoma (52). A phase I study of dabrafenib demonstrated intracranial responses in 9 of 10 melanoma patients (53) whereas a larger multicenter phase 2 study with single agent dabrafenib enrolled 172 patients with $B R A F^{V 600 E / K}$ mutant melanoma with brain metastases (54). BRAF mutated patients had improved intracranial responses, with $40 \%$ (29 of 74 ) of treatment naïve and $30 \%$ (20 of 65) of previously treated brain metastases patients responding to single agent dabrafenib.

The combination of BRAF inhibitor and MEK inhibitor was found to be superior with less adverse effects in the treatment of advanced melanoma $(55,56)$. The combination of dabrafenib and trametinib was evaluated in BRAF mutated metastatic melanoma patients with brain metastases in the COMBI-MB trial (57). Patients were enrolled into four cohorts. Cohort A included patients with $\mathrm{BRAF}^{\mathrm{V} 600 \mathrm{E}}$ mutation who had good 
performance status, no symptoms from brain metastases and had not received intracranial therapy. $\mathrm{BRAF}^{\mathrm{V} 600 \mathrm{E}}$ patients who had good performance status, asymptomatic brain metastases with progression of intracranial metastases after initial local therapy were enrolled to cohort $\mathrm{B}$. Cohort $\mathrm{C}$ had asymptomatic patients with a good performance status but had BRAFV600D/K/R mutation. Finally, cohort D had patients with symptomatic brain metastases, from metastatic melanoma with $\mathrm{BRAF}^{\mathrm{V} 600 \mathrm{E} / \mathrm{D} / \mathrm{K} / \mathrm{R}}$ mutation. The response rates in cohorts $\mathrm{A}$ through $\mathrm{D}$ were $58 \%$ (44 of 76 patients), 56\% (9 of 16 patients), $44 \%$ (7 of 16 patients), and 59\% (10 of 17 patients), respectively. These encouraging responses across all the cohorts make the combination of BRAF + MEK inhibitors a reasonable strategy in the management of patients with BRAF mutated metastatic melanoma with brain metastases. Studies with new BRAF and MEK inhibitor combinations will also provide more data $(58,59)$. BRAF directed therapy, dabrafenib plus trametinib is now approved for treatmentlung cancer patients where BRAF mutations are noted in about $2-4 \%$ of patients (60), however, their utility in lung cancer with brain metastases is yet to be evaluated.

\section{CDK PATHWAY ALTERATIONS}

Cell cyclin dependent kinases $(\mathrm{CDK} 4 / 6)$ play a role in transitioning cells from $\mathrm{G} 1$ to $\mathrm{S}$ phase of cell division. The phosphorylation of tumor suppressor proteins like retinoblastoma protein is a key function of CDK4/6 which leads to cell division and proliferation (61). CDKN2A alterations are common in hormone receptor positive breast cancer patients. Palbociclib, abemaciclib, and ribociclib are the three CDK inhibitors that are approved for management of hormone receptor positive advanced breast cancer. Whole exome analysis of matched brain metastases patients and primary tumors showed increased frequency of alterations which might sensitize brain metastases to CDK inhibitors (19). Currently, clinical trials with CDK inhibitors in patients with brain metastases are enrolling patients, including a phase 2 study of palbociclib in recurrent brain metastases (NCT 02896335).

\section{EGFR MUTATION}

Epidermal Growth Factor Receptor (EGFR) is a transmembrane protein of the Human Epidermal Receptor (HER) family. The HER family encompasses 4 different receptors namely: EGFR/erbB1/HER1, erbB2/HER2, erbB3/HER3, and erbB4/HER4 receptors. All these receptors have tyrosine kinase roles that activate signal transduction inducing cell proliferation. EGFR overexpression or mutations are common in NSCLC, head and neck cancer, and colon cancer.

EGFR targeted therapies have been successful in the treatment of advanced lung cancer. Gefitinib and erlotinib are the two first-generation EGFR-TKIs that have improved progression-free survival (PFS) in advanced EGFR-NSCLC patients $(62,63)$. In the pivotal studies leading to their FDA-approval, patients with brain metastases were excluded. Both gefitinib and erlotinib have CSF concentrations higher than inhibitory concentration in vitro, despite being substrates for efflux pumps $(64,65)$. More recently, studies have evaluated the efficacy of gefitinib and erlotinib in EGFR-NSCLC patients with brain metastases (66-68). For example, Wu et al. enrolled 48 NSCLC patients with intracranial progressive disease after initial platinum-based chemotherapy to receive erlotinib (67). Although patients were not enriched for EGFR, the intracranial PFS and overall survival (OS) was 10.1 and 18.9 months, respectively. With an aim of obtaining higher intracranial concentration for erlotinib, investigators tried higher pulse doses which show promising results (69-71). The combination of erlotinib and radiation therapy was evaluated in two studies $(66,68)$. In a phase 2 study, 40 patients with brain metastases from NSCLC were treated with erlotinib and WBRT (68). There was no increase in toxicity, and an impressive response rate of $60 \%$ was noted. The median OS was 11.8 months, and the median survival was 19.1 months in EGFR mutated patients. A larger phase 3 attempted to evaluate the efficacy of radiation therapy and erlotinib in NSCLC patients with 1-3 brain metastases. The study design included three groups: WBRT plus stereotactic radiosurgery (SRS), WBRT plus SRS plus temozolomide, and WBRT plus SRS plus erlotinib. The study did not meet accrual and was not enriched for EGFR mutant patients, and it did not show significant differences in OS. Significant toxicity was noted with the combination of WBRT plus erlotinib, with $\sim 50 \%$ of the patients experiencing serious adverse effects, including myocardial ischemia and hemorrhagic stroke. Gefitnib is another first generation TKI has modest intracranial activity $(72,73)$. The intracranial activity of afatinib was reported in a case series of 100 patients with brain metastases where afatinib in a compassionate use program, however, the median time to intracranial progression was 3.9 months. Osimertinib is an EGFR inhibitor with activity against T790M, a mutation that confers resistance to first and second generation EGFR tyrosine kinase inhibitors. Pooled analysis from two phase 2 studies of 50 patients with measurable brain metastases showed intracranial response rates of $54 \% ; 75 \%$ of patients at 9 months had an ongoing response (74). Most ongoing clinical trials with osimertinib have now allowed enrollment of patients with stable asymptomatic brain metastases. In the recently reported phase III clinical trial of upfront osimertinib, median intracranial PFS at 6 months was $87 \%$ in the osimertinib group compared to $71 \%$ in the standard EGFR-TKI group (75). This progression free survival benefit was sustained at 18 months. The CNS progression was lower in the osimertinib compared to standard EGFR-TKI (6 vs. 15\%) (76). Osimertinib has activity in leptomeningeal disease as well (77). At the initial efficacy assessment of a phase 1 clinical trial of osimertinib in EGFR mutant NSCLC with leptomeningeal disease, $33 \%$ (7 of 21 ) of patients were responding to treatment (77).

\section{HER2 ALTERATIONS}

HER2 receptor, a transmembrane EGFR receptor, with no known ligands for the HER2 receptor, is activated by 
homodimerization and heterodimerization (78). When activated, HER2 receptors lead to tumor growth, proliferation, and more invasiveness. The Ras/MAP kinase and PIK3/mTOR are the common downstream signaling pathways activated by HER2 overexpression and mutation. HER2 overexpression is primarily identified in $20 \%$ of breast cancer (79) but can be present in $30 \%$ of upper gastrointestinal malignancies like esophageal adenocarcinoma and gastro-esophageal junction carcinoma (80). HER2 overexpression generally indicates aggressive behavior (79). Several different strategies have been adopted to improve outcomes in these patients including monoclonal antibodies like trastuzumab, and pertuzumab, TKIs such as lapatinib, neratinib, tesevatinib, and the antibody drug conjugate trastuzumab-emtansine (T-DM1).

Trastuzumab was the first monoclonal antibody that showed improvement in OS in the metastatic, adjuvant, and neo-adjuvant setting $(81,82)$. However, a number of trastuzumab treated patients had intracranial disease recurrence. This is likely partly due to the inherent biology of HER2 overexpressing breast cancer, and partly because trastuzumab has poor penetration across the $\mathrm{BBB}(83,84)$. The plasma-to-CSF concentration of trastuzumab has been evaluated in patients with brain metastases by using immunoenzymatic tests (85). Notably, intracranial trastuzumab levels can change dramatically with radiation therapy; prior to radiation therapy the CSF to plasma levels of trastuzumab were reported to be low (1:420), with an increase (1:79) after radiotherapy. Other studies with radio-labeled-trastuzumab have corroborated this finding $(86,87)$. Although some retrospective studies have shown improvement in OS patients with brain metastases treated with trastuzumab, it may be due to improved extracranial disease control $(88,89)$. Pertuzumab showed promising clinical activity when added to a regimen containing trastuzumab in various clinical settings $(90,91)$. Clinical evidence of CNS penetration of pertuzumab was demonstrated in a demonstrating prolongation of the interval from treatment to development of CNS metastases, which was 15.0 months in the pertuzumab-treated population compared to 11.9 months (92). Lapatinib is a small molecule TKI inhibiting EGFR and HER2 receptor activation. In the absence of CNS metastases, lapatinib has an intracranial concentration of $3 \%$, which increases to $25 \%$ in the presence of brain metastases (93). This is change in intracranial concentration has been attributed to altered blood brain barrier by brain metastases. In a phase 2 study, 39 patients with HER2 overexpressing breast cancer and measurable brain metastases who progressed on trastuzumab were treated with lapatinib and results showed only one partial response (94). In a multicenter single arm study of lapatinib in combination with capecitabine (a nucleoside inhibitor), 29 of 45 patients (66\%) had a partial response (95). The combination of lapatinib and topotecan (a topoisomerase I inhibitor) failed to improve response rates compared to lapatinib and capecitabine (96). A combination of lapatinib and cabazitaxel (a microtubule inhibitor) has also been safely combined in brain metastases patients and the results of the phase 2 study have not been published (97). Neratinib, a newer HER2 targeting TKI approved for adjuvant treatment of breast cancer patients with HER2 overexpression was evaluated in HER2 overexpressing breast cancer brain metastases, the majority of which had progressed after WBRT (98), with an overall response of only $8 \%$. The combination of neratinib plus capecitabine was recently evaluated in a phase 2 clinical trial with encouraging preliminary results showing a 12 -month survival of $63 \%$ in 39 patients. Tesevatinib is another TKI which has shown safety and preliminary efficacy in brain metastases from breast and lung cancer patients $(99,100)$.

The antibody drug conjugate trastuzumab-emtansine ( $\mathrm{T}$ DM1) is an approved second line treatment option for metastatic HER2 overexpressing tumors after trastuzumab (101). Patients with brain metastases treated in the registration trial had improved survival with T-DM1 compared to lapatinib plus capecitabine (102).

\section{IMMUNOTHERAPY}

Monoclonal antibodies targeting immune-checkpoints (CTLA4 and PD-1/PDL-1) have revolutionized the management of several advanced malignancies, particularly melanoma and NSCLC. Initial studies with ipilimumab, a CTLA-4 antibody, in melanoma patients with brain metastases showed modest responses, which was largely impacted by use of dexamethasone (103). A recent open label, multiinstituitional phase 2 study evaluated the combination of ipilimumab and nivolumab (anti PD-1 antibody) in melanoma patients with asymptomatic untreated brain metastases (104). The primary endpoint for this study was intracranial benefit rate, defined by stable disease for 6 months, or response to treatment. Ninety four patients were enrolled in the trial, and the results were impressive with $57 \%$ patients meeting the primary end-point while $26 \%$ had complete response. Pembrolizumab is another anti PD-1 antibody which was studied in a single center phase 2 clinical trial of patients with brain metastases from melanoma or NSCLC (105). The melanoma arm accrued 23 patients and 6 of them had intracranial response with a median OS of 17 months (106). An interim analysis for 18 NSCLC patients reported an intracranial response rate of $33 \%$. These studies provide early but encouraging evidence for intracranial activity with these agents. An important limitation for immunotherapy is the use of dexamethasone for symptomatic brain metastases, and during radiation therapy.

\section{VEGF (VASCULAR ENDOTHELIAL GROWTH FACTOR) PATHWAY}

Angiogenesis and neovascularization play a critical role in the development of brain metastases, thus anti-angiogenic therapy could be a promising strategy. Bevacizumab is a monoclonal antibody which has an established track record of anti-VEGF activity. Preliminary results from a phase 2 trial of the combination of bevacizumab and carboplatin in breast cancer patients with brain metastases showed a response rate of $45 \%$ (107). The favorable changes in MRI appearance is likely 
TABLE 1 | Summary of selected studies of targeted therapies in brain metastases.

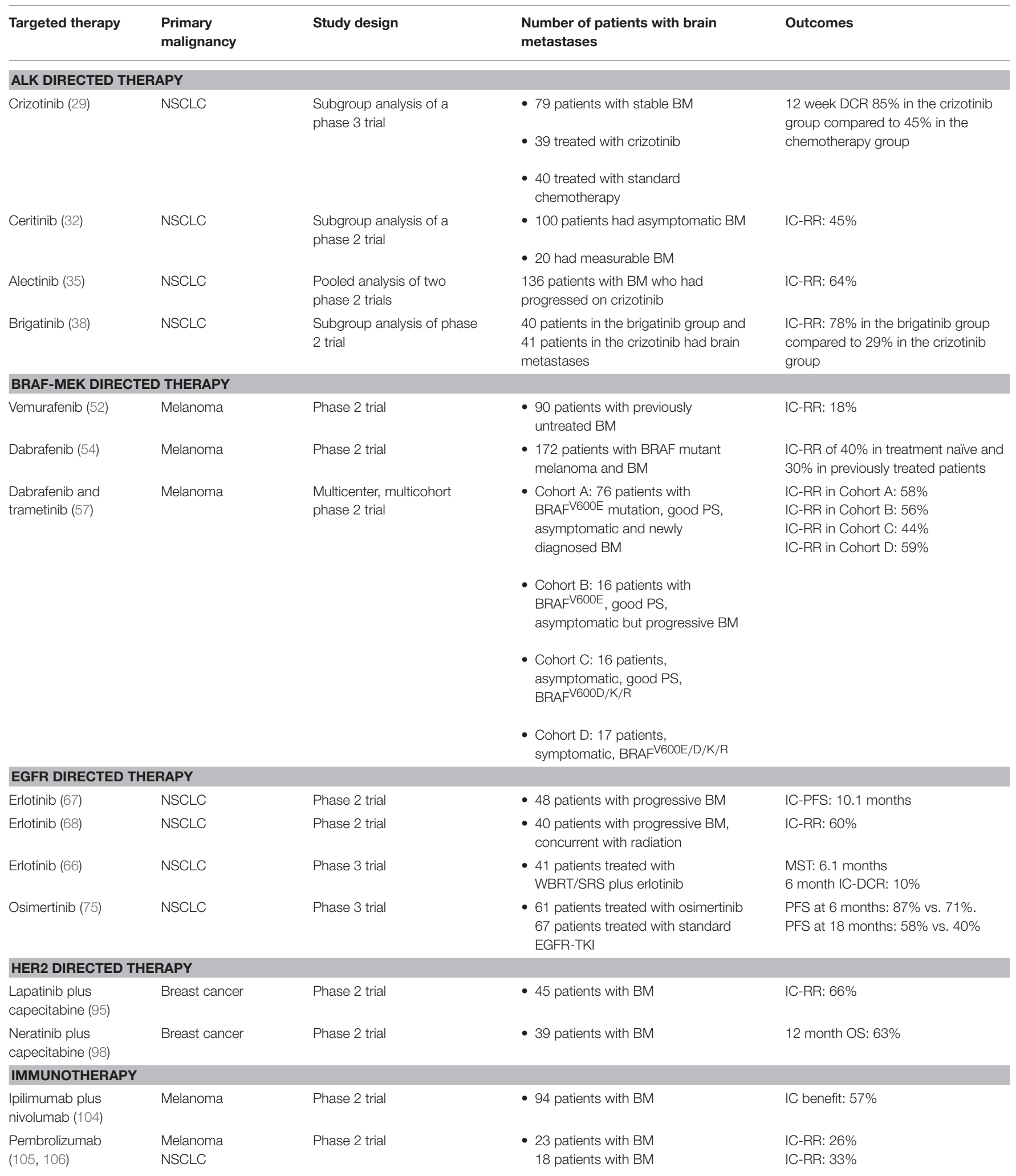

NSCLC, Non-small cell lung cancer; BM, brain metastases; DCR, disease control rate; IC-RR, Intracranial response rate; MST, median survival time; OS, overall survival; PFS, progression free survival; IC benefit, 6 month stable disease, complete or partial response. 
secondary to decreased inflammation from alteration of blood vessels by bevacizumab.

\section{CONCLUSION}

The management of CNS metastatic disease remains challenging. Surgery and radiation are still the most common approaches to the management of brain metastases. The minimal progress in the management of brain metastases can be attributed to the unique challenges in drug delivery to the CNS, and the limited understanding of the genetic heterogeneity in brain metastases compared to primary tumors. Furthermore, most clinical trials have historically excluded patients with CNS disease. Our knowledge of the genetics of brain metastases is increasing and new targeted therapies with improved CNS penetration are in development. Finally, clinical trials dedicated to patients with brain metastases in all malignancies with an emphasis on translational science will provide insight and therapeutic options for this patient population. Table 1 provides a summary of clinical trials with targeted agents for brain metastases.

\section{REFERENCES}

1. Meert AP, Paesmans M, Berghmans T, Martin B, Mascaux C, Vallot F, et al. Prophylactic cranial irradiation in small cell lung cancer: a systematic review of the literature with meta-analysis. BMC Cancer. (2001) 1:5. doi: 10.1186/1471-2407-1-5

2. Venur VA, Leone JP. Targeted therapies for brain metastases from breast cancer. Int J Mol Sci. (2016) 17: 1543. doi: 10.3390/ijms17091543

3. Venur VA, Funchain P, Kotecha R, Chao ST, Ahluwalia MS. Changing treatment paradigms for brain metastases from melanoma-part 1: diagnosis, prognosis, symptom control, and local treatment. Oncology. (2017) 31:602-6.

4. Gupta GP, Massagué J. Cancer metastasis: building a framework. Cell. (2006) 127:679-95. doi: 10.1016/j.cell.2006.11.001

5. Cooper JB, Ronecker JS, Tobias ME, Mohan AL, Hillard V, Murali R, et al. Molecular sequence of events and signaling pathways in cerebral metastases. Anticancer Res. (2018) 38:1859-77. doi: 10.21873/anticanres.12424

6. Tam WL, Weinberg RA. The epigenetics of epithelial-mesenchymal plasticity in cancer. Nat Med. (2013) 19:1438-49. doi: 10.1038/nm.3336

7. Xu J, Lamouille S, Derynck R. TGF-beta-induced epithelial to mesenchymal transition. Cell Re. (2009) 19:156-72. doi: 10.1038/cr.2009.5

8. Derynck R, Zhang YE. Smad-dependent and Smad-independent pathways in TGF-beta family signalling. Nature. (2003) 425:577-84. doi: 10.1038 /nature02006

9. Grände M, Franzen A, Karlsson JO, Ericson LE, Heldin NE, Nilsson M. Transforming growth factor- $\beta$ and epidermal growth factor synergistically stimulate epithelial to mesenchymal transition (EMT) through a MEKdependent mechanism in primary cultured pig thyrocytes. J Cell Sci. (2002) 115:4227-36. doi: 10.1242/jcs.00091

10. Davies MJ. The oxidative environment and protein damage. Biochim et Biophys Acta. (2005) 1703:93-109. doi: 10.1016/j.bbapap.2004.08.007

11. Bakin AV, Tomlinson AK, Bhowmick NA, Moses HL, Arteaga CL. Phosphatidylinositol 3-kinase function is required for transforming growth factor beta-mediated epithelial to mesenchymal transition and cell migration. J Biol Chem. (2000) 275:36803-10. doi: 10.1074/jbc.M005912200

12. Wilhelm I, Molnár J, Fazakas C, Haskó J, Krizbai IA. Role of the bloodbrain barrier in the formation of brain metastases. Int J Mol Sci. (2013) 14:1383-411. doi: 10.3390/ijms14011383

13. Eichler AF, Chung E, Kodack DP, Loeffler JS, Fukumura D, Jain RK. The biology of brain metastases-translation to new therapies. Nat Rev Clinical Oncol. (2011) 8:344-56. doi: 10.1038/nrclinonc.2011.58

\section{FUTURE DIRECTIONS}

A multi-disciplinary approach including primary medical oncologists, radiation oncologists, neuro-oncologists, and neurosurgeons is critical in the management patients with brain metastases. Histology and molecular profiling should guide treatment options. For specific malignancies such as melanoma and NSCLC, immune checkpoint inhibitiors have durable responses with and without radiation or surgery. Furthermore, patients with targetable driver mutations can be treated with novel systemic targeted agents with better CNS penetration than previously used chemotherapy. Dedicated clinical trials, brain metastases consortiums and a personalized approach to this patient population will focus on many remaining unanswered questions.

\section{AUTHOR CONTRIBUTIONS}

$\mathrm{VV}$, JC, and $\mathrm{PB}$ were involved in the initial planning, writing, and editing the manuscript.

14. Osswald M, Blaes J, Liao Y, Solecki G, Gömmel M, Berghoff AS, et al. Impact of blood-brain barrier integrity on tumor growth and therapy response in brain metastases. Clin Cancer Res. (2016) 22:6078-87. doi: 10.1158/1078-0432.ccr-16-1327

15. Lockman PR, Mittapalli RK, Taskar KS, Rudraraju V, Gril B, Bohn KA, et al. Heterogeneous blood-tumor barrier permeability determines drug efficacy in experimental brain metastases of breast cancer. Clin Cancer Res. (2010) 16:5664-78. doi: 10.1158/1078-0432.ccr-10-1564

16. Lin NU, Bellon JR, Winer EP. CNS metastases in breast cancer. J Clin Oncol. (2004) 22:3608-17. doi: 10.1200/jco.2004.01.175

17. de Vries NA, Beijnen JH, Boogerd W, van Tellingen O. Blood-brain barrier and chemotherapeutic treatment of brain tumors. Expert Rev Neurotherapeut. (2006) 6:1199-209. doi: 10.1586/14737175.6.8.1199

18. Steeg PS, Zimmer A, Gril B. Therapeutics for brain metastases, v3. Clin Cancer Res. (2016) 22:1-3. doi: 10.1158/1078-0432.ccr-16-2035

19. Brastianos PK, Carter SL, Santagata S, Cahill DP, Taylor-Weiner A, Jones RT, et al. Genomic characterization of brain metastases reveals branched evolution and potential therapeutic targets. Cancer Discovery. (2015) 5:116477. doi: 10.1158/2159-8290.cd-15-0369

20. Chen G, Chakravarti N, Aardalen K, Lazar AJ, Tetzlaff MT, Wubbenhorst $\mathrm{B}$, et al. Molecular profiling of patient-matched brain and extracranial melanoma metastases implicates the pi3k pathway as a therapeutic target. Clin Cancer Res. (2014) 20:5537-46. doi: 10.1158/1078-0432.CCR-13-3003

21. Ferguson SD, Zheng S, Xiu J, Zhou S, Khasraw M, Brastianos PK, et al. Profiles of brain metastases: prioritization of therapeutic targets. Int J Cancer. (2018) 143:3019-26. doi: 10.1002/ijc.31624

22. Morris SW, Kirstein MN, Valentine MB, Dittmer KG, Shapiro DN, Saltman DL, et al. Fusion of a kinase gene, ALK, to a nucleolar protein gene, NPM, in non-Hodgkin's lymphoma. Science. (1994) 263:1281-4.

23. Shaw AT, Engelman JA. ALK in Lung cancer: past, present, and future. J Clin Oncol. (2013) 31:1105-11. doi: 10.1200/jco.2012.44.5353

24. Soda M, Choi YL, Enomoto M, Takada S, Yamashita Y, Ishikawa S, et al. Identification of the transforming EML4-ALK fusion gene in non-small-cell lung cancer. Nature. (2007) 448:561-6. doi: 10.1038/nature05945

25. Rangachari D, Yamaguchi N, VanderLaan PA, Folch E, Mahadevan A, Floyd SR, et al. Brain metastases in patients with EGFR-mutated or ALKrearranged non-small-cell lung cancers. Lung Cancer. (2015) 88:108-11. doi: 10.1016/j.lungcan.2015.01.020

26. Metro G, Lunardi G, Floridi P, Pascali JP, Marcomigni L, Chiari R, et al. CSF concentration of crizotinib in Two ALK-Positive non-small-cell lung cancer 
patients with cns metastases deriving clinical benefit from treatment. $J$ Thor Oncol. (2015) 10:e26-7. doi: 10.1097/jto.0000000000000468

27. Costa DB, Kobayashi S, Pandya SS, Yeo WL, Shen Z, Tan W, et al. CSF concentration of the anaplastic lymphoma kinase inhibitor crizotinib. J Clin Oncol. (2011) 29:e443-5. doi: 10.1200/jco.2010.34.1313

28. Solomon BJ, Mok T, Kim DW, Wu YL, Nakagawa K, Mekhail T, et al. Firstline crizotinib versus chemotherapy in ALK-positive lung cancer. $N$ Engl J Med. (2014) 371:2167-77. doi: 10.1056/NEJMoa 1408440

29. Solomon BJ, Cappuzzo F, Felip E, Blackhall FH, Costa DB, Kim DW, et al. Intracranial efficacy of crizotinib versus chemotherapy in patients with advanced ALK-positive non-small-cell lung cancer: results from PROFILE 1014. J Clin Oncol. (2016) 34:2858-65. doi: 10.1200/jco.2015.63.5888

30. Costa DB, Shaw AT, Ou SH, Solomon BJ, Riely GJ, Ahn MJ, et al. Clinical experience with crizotinib in patients with advanced ALK-rearranged nonsmall-cell lung cancer and brain metastases. J Clin Oncol. (2015) 33:1881-8. doi: 10.1200/jco.2014.59.0539

31. Shaw A, Mehra R, Tan DSW, Felip E, Chow LQW, Camidge DR, et al. BM-32 Ceritinib (LDK378) for treatment of patients with ALK-rearranged $(\mathrm{ALK}+)$ non-small cell lung cancer (NSCLC) and brain metastases (BM) in the ASCEND-1 trial. Neuro-oncology. (2014) 16 (Suppl. 5):v39. doi: $10.1093 /$ neuonc/nou 240.32

32. Crinò L, Ahn MJ, De Marinis F, Groen HJ, Wakelee H, Hida T, et al. Multicenter phase II study of whole-body and intracranial activity with ceritinib in patients with ALK-rearranged non-small-cell lung cancer previously treated with chemotherapy and crizotinib: results from ASCEND2. J Clin Oncol. (2016) 34:2866-73. doi: 10.1200/jco.2015.65.5936

33. Nishio M, Nakagawa K, Mitsudomi T, Yamamoto N, Tanaka T, Kuriki H, et al. Analysis of central nervous system efficacy in the J-ALEX study of alectinib versus crizotinib in ALK-positive non-small-cell lung cancer. Lung Cancer. (2018) 121:37-40. doi: 10.1016/j.lungcan.2018.04.015

34. Peters S, Camidge DR, Shaw AT, Gadgeel S, Ahn JS, Kim DW, et al. Alectinib versus crizotinib in untreated ALK-positive non-small-cell lung cancer. $N$ Engl J Med. (2017) 377:829-38. doi: 10.1056/NEJMoa1704795

35. Gadgeel SM, Shaw AT, Govindan R, Gandhi L, Socinski MA, Camidge DR, et al. Pooled analysis of CNS response to alectinib in two studies of pretreated patients with ALK-positive non-small-cell lung cancer. J Clin Oncol. (2016) 34:4079-85. doi: 10.1200/JCO.2016.68.4639

36. Gettinger S, Kim D-W, Tiseo M, Langer C, Ahn MJ, Shaw A, et al. OA08.06 brigatinib activity in patients with ALK + NSCLC and intracranial CNS metastases in two clinical trials. J Thor Oncol. (2017) 12:S273-S74. doi: 10.1016/j.jtho.2016.11.271

37. Camidge DR, Kim DW, Tiseo M, Langer CJ, Ahn MJ, Shaw AT, et al. Exploratory analysis of brigatinib activity in patients with anaplastic lymphoma kinase-positive non-small-cell lung cancer and brain metastases in two clinical trials. J Clin Oncol. (2018) 36:2693-701. doi: $10.1200 /$ jco.2017.77.5841

38. Camidge DR, Kim HR, Ahn MJ, Yang JC, Han JY, Lee JS, et al. Brigatinib versus crizotinib in ALK-positive non-small-cell lung cancer. $N$ Engl J Med. (2018) 379:2027-39. doi: 10.1056/NEJMoa1810171

39. Acquaviva J, Wong R, Charest A. The multifaceted roles of the receptor tyrosine kinase ROS in development and cancer. Biochim et Biophys Acta. (2009) 1795:37-52. doi: 10.1016/j.bbcan.2008.07.006

40. Gainor JF, Tseng D, Yoda S, Dagogo-Jack I, Friboulet L, Lin JJ, et al. Patterns of metastatic spread and mechanisms of resistance to crizotinib in ROS1-positive non-small-cell lung cancer. JCO Precis Oncol. (2017) 2017. doi: $10.1200 /$ po. 17.00063

41. Shaw AT, Ou SH, Bang YJ, Camidge DR, Solomon BJ, Salgia R, et al. Crizotinib in ROS1-rearranged non-small-cell lung cancer. N Engl J Med. (2014) 371:1963-71. doi: 10.1056/NEJMoa1406766

42. Drilon AE, Subbiah V, Oxnard GR, Bauer TM, Velcheti V, Lakhani NJ, et al. A phase 1 study of LOXO-292, a potent and highly selective RET inhibitor, in patients with RET-altered cancers. J Clin Oncol. (2018) 36 (Suppl. 15):102-02. doi: 10.1200/JCO.2018.36.15_suppl.102

43. Khotskaya YB, Holla VR, Farago AF, Mills Shaw KR, Meric-Bernstam F, Hong DS. Targeting TRK family proteins in cancer. Pharmacol. Therap. (2017) 173:58-66. doi: 10.1016/j.pharmthera.2017.02.006

44. Drilon A, Siena S, Ou SI, Patel M, Ahn MJ, Lee J, et al. Safety and antitumor activity of the multitargeted pan-TRK, ROS1, and ALK inhibitor entrectinib: combined results from two phase I trials (ALKA-372-001 and STARTRK-1). Cancer Discov. (2017) 7:400-9. doi: 10.1158/2159-8290.cd-16-1237

45. Hong DS, Dowlati A, Burris HA III, Lee MS, Brose MS, Farago TM, et al. Clinical safety and activity from a phase 1 study of LOXO-101, a selective TRKA/B/C inhibitor, in solid-tumor patients with NTRK gene fusions. Eur J Cancer. (2017) 72:S148. doi: 10.1016/S0959-8049(17)30561-0

46. Velcheti V, Bauer T, Subbiah V, Cabanillias M, Lakhani L, Wirth G, et al. OA 12.07 LOXO-292, a potent, highly selective RET inhibitor, in MKI-resistant RET fusion-positive lung cancer patients with and without brain metastases. J Thor Oncol. (2017) 12:S1778. doi: 10.1016/j.jtho.2017.09.399

47. Subbiah V, Gainor JF, Rahal R, Brubaker JD, Kim JL, Maynard M, et al. Precision targeted therapy with BLU-667 for RET-driven cancers. Cancer Discov. (2018) 8:836-49. doi: 10.1158/2159-8290.cd-18-0338

48. Garnett MJ, Marais R. Guilty as charged: B-RAF is a human oncogene. Cancer Cell. (2004) 6:313-9. doi: 10.1016/j.ccr.2004.09.022

49. Cantwell-Dorris ER, O'Leary JJ, Sheils OM. BRAFV600E: implications for carcinogenesis and molecular therapy. Mol Cancer Therap. (2011) 10:385-94. doi: 10.1158/1535-7163.mct-10-0799

50. Cheng L, Lopez-Beltran A, Massari F, MacLennan GT, Montironi R. Molecular testing for BRAF mutations to inform melanoma treatment decisions: a move toward precision medicine. Modern Pathol. (2018) 31:2438. doi: 10.1038/modpathol.2017.104

51. Long GV, Margolin KA. Multidisciplinary approach to brain metastasis from melanoma: the emerging role of systemic therapies. Am Soc Clin Oncol Educ Book. (2013) 31:393-8. doi: 10.1200/EdBook_AM.2013.33.393

52. Dummer R, Goldinger SM, Turtschi CP, Eggmann NB, Michielin O, Mitchell $\mathrm{L}$, et al. Vemurafenib in patients with BRAF(V600) mutation-positive melanoma with symptomatic brain metastases: final results of an open-label pilot study. Eur J Cancer. (2014) 50:611-21. doi: 10.1016/j.ejca.2013.11.002

53. Falchook GS, Long GV, Kurzrock R, Kim KB, Arkenau TH, Brown MP, et al. Dabrafenib in patients with melanoma, untreated brain metastases, and other solid tumours: a phase 1 dose-escalation trial. Lancet. (2012) 379:1893-901. doi: 10.1016/s0140-6736(12)60398-5

54. Long GV, Trefzer U, Davies MA, Kefford RF, Ascierto PA, Chapman PB, et al. Dabrafenib in patients with Val600Glu or Val600Lys BRAF-mutant melanoma metastatic to the brain (BREAK-MB): a multicentre, open-label, phase 2 trial. Lancet Oncol. (2012) 13:1087-95. doi: 10.1016/s1470-2045(12)70431-x

55. Larkin J, Ascierto PA, Dréno B, Atkinson V, Liszkay G, Maio M, et al. Combined vemurafenib and cobimetinib in BRAF-mutated melanoma. N Engl J Med. (2014) 371:1867-76. doi: 10.1056/NEJMoa14 08868

56. Robert C, Karaszewska B, Schachter J, Rutkowski P, Mackiewicz A, Stroiakovski D, et al. Improved overall survival in melanoma with combined dabrafenib and trametinib. N Engl J Med. (2015) 372:30-39. doi: 10.1056/NEJMoa1412690

57. Davies MA, Saiag P, Robert C, Grob JJ, Flaherty KT, Arance A, et al. Dabrafenib plus trametinib in patients with BRAFV600mutant melanoma brain metastases (COMBI-MB): a multicentre, multicohort, open-label, phase 2 trial. Lancet Oncol. (2017) 18:863-73. doi: 10.1016/s1470-2045(17)30429-1

58. Yee MK, Lin Y, Gorantla VC, Butterfield LH, Kluger HM, Chapman PB, et al. Phase 2 study of cobimetinib in combination with vemurafenib in active melanoma brain metastases (coBRIM-B). J Clin Oncol. (2015) 33 (Suppl. 15):TPS9088-88. doi: 10.1200/jco.2015.33.15_suppl.tps9088

59. Dummer R, Ascierto PA, Gogas HJ, Arance A, Mandala M, Liszkay G, et al. Encorafenib plus binimetinib versus vemurafenib or encorafenib in patients with BRAF-mutant melanoma (COLUMBUS): a multicentre, open-label, randomised phase 3 trial. Lancet Oncol. (2018) 19:603-15. doi: 10.1016/s1470-2045(18)30142-6

60. Baik CS, Myall NJ, Wakelee HA. Targeting BRAF-mutant non-small cell lung cancer: from molecular profiling to rationally designed therapy. Oncologist. (2017) 22:786-69. doi: 10.1634/theoncologist.2016-0458

61. Asghar U, Witkiewicz AK, Turner NC, Knudsen ES. The history and future of targeting cyclin-dependent kinases in cancer therapy. Nat Rev Drug Discov. (2015) 14:130-46. doi: 10.1038/nrd4504

62. Rosell R, Carcereny E, Gervais R, Vergnenegre A, Massuti B, Felip E, et al. Erlotinib versus standard chemotherapy as first-line treatment for European 
patients with advanced EGFR mutation-positive non-small-cell lung cancer (EURTAC): a multicentre, open-label, randomised phase 3 trial. Lancet Oncol. (2012) 13:239-46. doi: 10.1016/S1470-2045(11)70393-X

63. Maemondo M, Inoue A, Kobayashi K, Sugawara S, Oizumi S, Isobe H, et al. Gefitinib or chemotherapy for non-small-cell lung cancer with mutated EGFR. N Engl J Med. (2010) 362:2380-88. doi: 10.1056/NEJMoa0909530

64. Chamberlain MC, Baik CS, Gadi VK, Bhatia S, Chow LQ. Systemic therapy of brain metastases: non-small cell lung cancer, breast cancer, and melanoma. Neuro-oncology. (2017) 19:11-i24. doi: 10.1093/neuonc/now197

65. Togashi Y, Masago K, Fukudo M, Terada T, Fujita S, Irisa K, et al. Cerebrospinal fluid concentration of erlotinib and its active metabolite OSI420 in patients with central nervous system metastases of non-small cell lung cancer. J Thor Oncol. (2010) 5:950-5. doi: 10.1097/JTO.0b013e3181e2138b

66. Sperduto PW, Wang M, Robins HI, Schell MC, Werner-Wasik M, Komaki $\mathrm{R}$, et al. A phase 3 trial of whole brain radiation therapy and stereotactic radiosurgery alone versus WBRT and SRS with temozolomide or erlotinib for non-small cell lung cancer and 1 to 3 brain metastases: Radiation Therapy Oncology Group 0320. Int J Rad Oncol Biol Phy. (2013) 85:1312-8. doi: 10.1016/j.ijrobp.2012.11.042

67. Wu YL, Zhou C, Cheng Y, Lu S, Chen GY, Huang C, et al. Erlotinib as second-line treatment in patients with advanced non-small-cell lung cancer and asymptomatic brain metastases: a phase II study (CTONG-0803). Ann Oncol. (2013) 24:993-9. doi: 10.1093/annonc/mds529

68. Welsh JW, Komaki R, Amini A, Munsell MF, Unger W, Allen PK, et al. Phase II trial of erlotinib plus concurrent whole-brain radiation therapy for patients with brain metastases from non-small-cell lung cancer. J Clin Oncol. (2013) 31:895-902. doi: 10.1200/jco.2011.40.1174

69. Yu HA, Sima CS, Reales D, Jordan S, Rudin CM, Kris MG, et al. A phase I study of twice weekly pulse dose and daily low dose erlotinib as initial treatment for patients (pts) with EGFR-mutant lung cancers. J Clin Oncol. (2015) 33 (Suppl. 15):8017-17. doi: 10.1200/jco.2015.33.15_suppl.8017

70. Togashi Y, Masago K, Fukudo M, Tsuchido Y, Okuda C, Kim YH, et al. Efficacy of increased-dose erlotinib for central nervous system metastases in non-small cell lung cancer patients with epidermal growth factor receptor mutation. Cancer Chemother Pharmacol. (2011) 68:1089-92. doi: $10.1007 / \mathrm{s} 00280-011-1691-\mathrm{z}$

71. Jackman DM, Mach SL, Heng JC, Rabin MS, Barbie DA, Gandhi L, et al. Pulsed dosing of erlotinib for central nervous system (CNS) progression in EGFR-mutant non-small cell lung cancer (NSCLC). J Clin Oncol. (2013) 31 (Suppl. 15):8116-16. doi: 10.1200/jco.2013.31.15_suppl.8116

72. Ceresoli GL, Cappuzzo F, Gregorc V, Bartolini S, Crinò L, Villa E. Gefitinib in patients with brain metastases from non-small-cell lung cancer: a prospective trial. Ann Oncol. (2004) 15:1042-7. doi: 10.1093/annonc/mdh276

73. Pesce GA, Klingbiel D, Ribi K, Zouhair A, von Moos R, Schlaeppi M, et al. Outcome, quality of life and cognitive function of patients with brain metastases from non-small cell lung cancer treated with whole brain radiotherapy combined with gefitinib or temozolomide. A randomised phase II trial of the Swiss Group for Clinical Cancer Research (SAKK 70/03). Eur J Cancer. (2012) 48:377-84. [published Online First: 2011/11/19] doi: 10.1016/j.ejca.2011.10.016

74. Goss G, Tsai CM, Shepherd FA, Ahn MJ, Bazhenova L, Crinò L, et al. CNS response to osimertinib in patients with T790M-positive advanced NSCLC: pooled data from two phase II trials. Ann Oncol. (2018) 29:687-93. doi: $10.1093 /$ annonc/mdx 820

75. Reungwetwattana T, Nakagawa K, Cho BC, Cobo M, Cho EK, Bertolini A, et al. CNS response to osimertinib versus standard epidermal growth factor receptor tyrosine kinase inhibitors in patients with untreated EGFR-mutated advanced non-small-cell lung cancer. J Clin Oncol. (2018) 36:3290-3297. doi: $10.1200 /$ jco.2018.78.3118

76. Soria JC, Ohe Y, Vansteenkiste J, Reungwetwattana T, Chewaskulyong B, Lee $\mathrm{KH}$, et al. Osimertinib in untreated EGFR-mutated advanced non-small-cell lung cancer. N Engl J Med. (2018) 378:113-25. doi: 10.1056/NEJMoa1713137

77. Cho BC, Ahn M-J, Lee J-S, Kim D-W, Kim S-W, John T, et al. Phase I study (BLOOM) of AZD3759, a BBB penetrable EGFR inhibitor, in EGFRm NSCLC patients with leptomeningeal metastasis (LM) who progressed after other anti-cancer therapy. J Clin Oncol. (2017) 35(Suppl. 15):2069-69. doi: 10.1200/JCO.2017.35.15_suppl.2069
78. Schettini F, Buono G, Cardalesi C, Desideri I, De Placido S, Del Mastro L. Hormone receptor/human epidermal growth factor receptor 2-positive breast cancer: where we are now and where we are going. Cancer Treat Rev. (2016) 46:20-6. doi: 10.1016/j.ctrv.2016.03.012

79. Gingras I, Gebhart G, de Azambuja E, Piccart-Gebhart M. HER2-positive breast cancer is lost in translation: time for patient-centered research. Nat Rev Clin Oncol. (2017) 14:669. doi: 10.1038/nrclinonc.2017.96

80. Smyth EC, Lagergren J, Fitzgerald RC, Lordick F, Shah MA, Lagergren P, et al. Oesophageal cancer. Nat Rev Dis Prim. (2017) 3:17048. doi: $10.1038 /$ nrdp. 2017.48

81. Piccart-Gebhart MJ, Procter M, Leyland-Jones B, Goldhirsch A, Untch M, Smith I, et al. Trastuzumab after adjuvant chemotherapy in HER2-positive breast cancer. $N$ Engl J Med. (2005) 353:1659-72. doi: 10.1056/NEJMoa052306

82. Slamon DJ, Leyland-Jones B, Shak S, Fuchs H, Paton V, Bajamonde A, et al. Use of chemotherapy plus a monoclonal antibody against HER2 for metastatic breast cancer that overexpresses HER2. N Engl J Med. (2001) 344:783-92. doi: 10.1056/nejm200103153441101

83. Lin NU, Gaspar LE, Soffietti R. Breast cancer in the central nervous system: multidisciplinary considerations and management. Am Soc Clin Oncol Edu Book. (2017) 37:45-56. doi: 10.14694/edbk_175338

84. Pestalozzi BC, Brignoli S. Trastuzumab in CSF. J Clin Oncol. (2000) 18:234951. doi: 10.1200/JCO.2000.18.11.2349

85. Stemmler HJ, Schmitt M, Willems A, Bernhard H, Harbeck N, Heinemann V. Ratio of trastuzumab levels in serum and cerebrospinal fluid is altered in HER2-positive breast cancer patients with brain metastases and impairment of blood-brain barrier. Anti-Cancer Drugs. (2007) 18:23-8. doi: 10.1097/01.cad.0000236313.50833.ee

86. Dijkers EC, Oude Munnink TH, Kosterink JG, Brouwers AH, Jager PL, de Jong JR, et al. Biodistribution of 89Zr-trastuzumab and PET imaging of HER2-positive lesions in patients with metastatic breast cancer. Clin Pharmacol Therap. (2010) 87:586-92. doi: 10.1038/clpt.2010.12

87. Tamura K, Kurihara H, Yonemori K, Tsuda H, Suzuki J, Kono Y, et al. 64CuDOTA-trastuzumab PET imaging in patients with HER2-positive breast cancer. J Nuclear Med. (2013) 54:1869-75. doi: 10.2967/jnumed.112.118612

88. Le Scodan R, Jouanneau L, Massard C, Gutierrez M, Kirova Y, Cherel P, et al. Brain metastases from breast cancer: prognostic significance of HER2 overexpression, effect of trastuzumab and cause of death. BMC Cancer. (2011) 11:395. doi: 10.1186/1471-2407-11-395

89. Park IH, Ro J, Lee KS, Nam BH, Kwon Y, Shin KH. Trastuzumab treatment beyond brain progression in HER2-positive metastatic breast cancer. Ann Oncol. (2009) 20:56-62. doi: 10.1093/annonc/mdn539

90. Baselga J, Swain SM. CLEOPATRA: a phase III evaluation of pertuzumab and trastuzumab for HER2-positive metastatic breast cancer. Clin Breast Cancer. (2010) 10:489-91. doi: 10.3816/CBC.2010.n.065

91. von Minckwitz G, Procter M, de Azambuja E, Zardavas D, Benyunes M, Viale G, et al. Adjuvant pertuzumab and trastuzumab in early HER2-positive breast cancer. N Engl J Med. (2017) 377:122-31. doi: 10.1056/NEJMoa1703643

92. Swain SM, Baselga J, Miles D, Im YH, Quah C, Lee LF, et al. Incidence of central nervous system metastases in patients with HER2-positive metastatic breast cancer treated with pertuzumab, trastuzumab, and docetaxel: results from the randomized phase III study CLEOPATRA. Ann Oncol. (2014) 25:1116-21. doi: 10.1093/annonc/mdu133

93. Taskar KS, Rudraraju V, Mittapalli RK, Samala R, Thorsheim HR, Lockman $\mathrm{J}$, et al. Lapatinib distribution in HER2 overexpressing experimental brain metastases of breast cancer. Pharma Res. (2012) 29:770-81. doi: 10.1007/s11095-011-0601-8

94. Lin NU, Carey LA, Liu MC, Younger J, Come SE, Ewend M, et al. Phase II trial of lapatinib for brain metastases in patients with human epidermal growth factor receptor 2-positive breast cancer. J Clin Oncol. (2008) 26:19939. doi: 10.1200/jco.2007.12.3588

95. Bachelot T, Romieu G, Campone M, Diéras V, Cropet C, Dalenc F, et al. Lapatinib plus capecitabine in patients with previously untreated brain metastases from HER2-positive metastatic breast cancer (LANDSCAPE): a single-group phase 2 study. Lancet Oncol. (2013) 14:64-71. doi: 10.1016/s1470-2045(12)70432-1 
96. Lin NU, Eierman W, Greil R, Campone M, Kaufman B, Steplewski $\mathrm{K}$, et al. Randomized phase II study of lapatinib plus capecitabine or lapatinib plus topotecan for patients with HER2-positive breast cancer brain metastases. J Neuro-Oncology. (2011) 105:613-20. doi: 10.1007/s11060-0110629-y

97. Yardley DA, Hart LL, Ward PJ, Wright GL, Shastry M, Finney L, et al. Cabazitaxel plus lapatinib as therapy for HER2+ metastatic breast cancer with intracranial metastases: results of a dose-finding study. Clin Breast Cancer. (2018) 18:e781-7. doi: 10.1016/j.clbc.2018. 03.004

98. Freedman R, Gelman R, Melisko M, Anders C, Moy B, Blackwell $\mathrm{K}$, et al. TBCRC 022: Phase II trial of neratinib + capecitabine for patients (Pts) with human epidermal growth factor receptor 2 (HER2+) breast cancer brain metastases (BCBM). J Clin Oncol. (2017) 35:1005. doi: 10.1200/JCO.2017.35.15_suppl.1005

99. Berz D, Subrananiam D, Tonra J, Berger M, Ross Camidge D. P2.03b-016 tesevatinib in NSCLC patients with EGFR activating mutations and brain metastases (BM) or leptomeningeal metastases (LM). J Thor Oncol. (2017) 12:S942-S43. doi: 10.1016/j.jtho.2016.11.1297

100. Lin NU, Freedman RA, Miller K, Jhaveri KL, Eiznhamer DA, Berger MS, et al. Determination of the maximum tolerated dose (MTD) of the CNS penetrant tyrosine kinase inhibitor (TKI) tesevatinib administered in combination with trastuzumab in HER2 + patients with metastatic breast cancer (BC). J Clin Oncol. (2016) 34 (Suppl. 15):514. doi: 10.1200/JCO.2016.34. 15_suppl.514

101. Verma S, Miles D, Gianni L, Krop IE, Welslau M, Baselga J, et al. Trastuzumab emtansine for HER2-positive advanced breast cancer. N Engl J Med. (2012) 367:1783-91. doi: 10.1056/NEJMoa 1209124

102. Krop IE, Lin NU, Blackwell K, Guardino E, Huober J, Lu M, et al. Trastuzumab emtansine (T-DM1) versus lapatinib plus capecitabine in patients with HER2-positive metastatic breast cancer and central nervous system metastases: a retrospective, exploratory analysis in EMILIA. Ann Oncol. (2015) 26:113-9. doi: 10.1093/annonc/mdu486
103. Margolin K, Ernstoff MS, Hamid O, Lawrence D, McDermott D, Puzanov I, et al. Ipilimumab in patients with melanoma and brain metastases: an open-label, phase 2 trial. Lancet Oncol. (2012) 13:459-65. doi: 10.1016/s1470-2045(12)70090-6

104. Tawbi HA, Forsyth PA, Algazi A, Hamid O, Hodi FS, Moschos SJ, et al. Combined nivolumab and ipilimumab in melanoma metastatic to the brain. N Engl J Med. (2018) 379:722-30. doi: 10.1056/NEJMoa1805453

105. Goldberg SB, Gettinger SN, Mahajan A, Chiang AC, Herbst RS, Sznol $\mathrm{M}$, et al. Pembrolizumab for patients with melanoma or non-small-cell lung cancer and untreated brain metastases: early analysis of a nonrandomised, open-label, phase 2 trial. Lancet Oncol. (2016) 17:976-83. doi: 10.1016/s1470-2045(16)30053-5

106. Kluger HM, Chiang V, Mahajan A, Zito CR, Sznol M, Tran T, et al. Longterm survival of patients with melanoma with active brain metastases treated with pembrolizumab on a phase II trial. J Clin Oncol. (2019) 37:52-60. doi: 10.1200/jco.18.00204

107. Lin NU, Gelman RS, Younger WJ, Sohi J, Freedman RA, Gregory Sorensen A, et al. Phase II trial of carboplatin (C) and bevacizumab (BEV) in patients (pts) with breast cancer brain metastases (BCBM). J Clin Oncol. (2013) 31 (Suppl. 15):513. doi: 10.1200/jco.2013.31.15_suppl.513

Conflict of Interest Statement: PB has received speaker's honorarium from Genentech, and Merck and is a consultant for Lilly, Tesaro, Angiochem and Genentech-Roche. PB has also received grant support to MGH from Merck, BMS and Pfizer. VV received honorarium from Elsevier. JC is a consultant for Sanofi-Genzyme.

Copyright (c) 2019 Venur, Cohen and Brastianos. This is an open-access article distributed under the terms of the Creative Commons Attribution License (CC BY). The use, distribution or reproduction in other forums is permitted, provided the original author(s) and the copyright owner(s) are credited and that the original publication in this journal is cited, in accordance with accepted academic practice. No use, distribution or reproduction is permitted which does not comply with these terms. 